\title{
A randomized clinical trial to determine the effect of angiotensin inhibitors reduction on creatinine clearance and haemoglobin in heart failure patients with chronic kidney disease and anaemia
}

\author{
S. Pita-Fernández, ${ }^{1}$ T. Chouciño-Fernández, ${ }^{2}$ J. Juega-Puig, ${ }^{2}$ T. Seoane-Pillado, ${ }^{1}$ \\ B. López-Calviño, ${ }^{1}$ S. Pértega-Díaz, ${ }^{1}$ J.-D. Pedreira-Andrade, ${ }^{2}$ V. Gil-Guillén ${ }^{3}$ \\ ${ }^{1}$ Division of Clinical Epidemiology, Complejo Hospitalario Universitario A Coruña (CHUAC), SERGAS, \\ Universidade de A Coruña, A Coruña, Spain \\ ${ }^{2}$ Department of Internal Medicine, Complejo Hospitalario Universitario A Coruña (CHUAC), SERGAS, A \\ Coruña, Spain \\ ${ }^{3}$ Miguel Hernández University, Alicante, Spain
}

\begin{abstract}
Summary
Background. Chronic kidney disease is a common comorbidity in elderly patients with heart failure. Evidence supports the use of angiotensin inhibitors for patients with heart failure. However, there is little evidence with which to assess the risk and benefits of this treatment in elderly patients with renal dysfunction.

Objective. To determine the efficacy and safety of angiotensin inhibitor reduction in patients with heart failure, chronic kidney disease and anaemia.

Study design. Open randomized controlled clinical trial.

Setting. Complexo Hospitalario Universitario A Coruña (Spain).

Patients. Patients $\geq 50$ years old, with heart failure, haemoglobin $(\mathrm{Hb})<12 \mathrm{mg} / \mathrm{dl}$ and creatinine clearance $<60 \mathrm{ml} / \mathrm{min} / 1.73 \mathrm{~m}^{2}$ admitted to hospital, in treatment with angiotensin inhibitors. Informed consent and Ethical Review Board approval were obtained.

Intervention. A 50\% reduction of angiotensin inhibitor dose of the basal treatment on admission $(n=30)$ in the intervention group. Control group $(n=16)$ with the standard basal dose.

Main outcome measure. Primary outcome was difference in $\mathrm{Hb}(\mathrm{gr} / \mathrm{dl})$, creatinine clearance $\left(\mathrm{ml} / \mathrm{min} / 1.73 \mathrm{~m}^{2}\right)$ and protein $\mathrm{C}(\mathrm{mg} / \mathrm{dl})$ between admission and 1-3 months after discharge. Secondary outcome was survival at 6-12 months after discharge.

Results. Patients in the intervention group experienced an improvement in $\mathrm{Hb}(10.62-11.47 \mathrm{~g} / \mathrm{dl})$, creatinine clearance $\left(32.5 \mathrm{ml} / \mathrm{min} / 1.73 \mathrm{~m}^{2}\right.$ to $\left.42.9 \mathrm{ml} / \mathrm{min} / 1.73 \mathrm{~m}^{2}\right)$, and a decrease in creatinine levels $(1.98-$ $1.68 \mathrm{mg} / \mathrm{dl})$ and protein $\mathrm{C}(3.23 \mathrm{mg} / \mathrm{dl}$ to $1.37 \mathrm{mg} / \mathrm{dl})$. There were no significant differences in these variables in the control group. Survival at 6 and 12 months in the intervention and control group was $86.7 \%$ vs. $75 \%$ and $69.3 \%$ vs. $50 \%$, respectively.

Conclusion. The reduction of the dose of angiotensin inhibitors in the intervention group resulted in an improvement in anaemia and kidney function, decreased protein $\mathrm{C}$ and an increased survival rate.
\end{abstract}




\section{Introduction}

As a result of the progressive ageing of the population, heart failure and renal dysfunction frequently coexist in the same patient. Worsening renal function in patients with decompensated heart failure has an impact on short and long-term morbidity and mortality [1,2] Gottlieb et al. [3] have shown that even a small increase in serum creatinine, for example $0.1 \mathrm{mg} / \mathrm{dl}$, will worsen the outcome of these patients.

Evidence-based treatment of heart failure is underused in patients with heart failure/chronic kidney disease because of concerns regarding the side effects of medication [1, 2, 4] Few prospective clinical trials have been carried out to define either the risk/benefit ratio of treatments in this population or to support dose adjustments [1], as a result of which little evidence is available to guide clinicians in the optimal management of patients with both conditions [5].

A wide range of complex pathophysiological interactions link the heart and kidney [3], and have been grouped under the term 'cardiorenal syndrome'. A large number of patients are also affected by cardiorenal anaemia syndrome [6].

Anaemia is commonly found in patients with heart failure, regardless of the presence of renal parenchymal disease. The incidence of anaemia increased from $9 \%$ for patients with New York Heart Association (NYHA) class I to 79\% for NYHA class IV, as reported by Silveberg [7]. Each $1 \mathrm{~g} / \mathrm{dl}$ decrease in serum haemoglobin was associated with increases in left ventricular dilatation and left ventricular hypertrophy, which in turn were associated with worsening renal function [8].

The mechanism of anaemia in chronic heart failure is almost certainly multifactorial. Congestion with renal sodium and water retention will lead to haemodilution [9, 10]. When worsening renal function occurs in heart failure patients, it may lead to relative erythropoietin deficiency $[11,12]$. Inflammation and increased cytokine production occur with heart failure and can suppress erythrocytosis of the bone marrow [13, 14]. Iron and vitamin deficiency are also common and may contribute to anaemia [12]. Furthermore, angiotensin inhibitors cause a reduction in haemoglobin by decreasing erythropoietin [15] and by preventing the breakdown of the haematopoiesis inhibitor $\mathrm{N}$-acetyl-seryl-aspartyl-lysyl-proline [16].

An analysis of the database of the Study of LV Dysfunction (SOLVD) by Al-Ahmad et al. [17] showed that for every $1 \%$ decrease in the haematocrit, the mortality rate increases by $2.7 \%$. Moreover, a small number of studies in chronic heart failure patients have shown significant improvement in outcomes by increasing the haemoglobin level from $12 \mathrm{~g} / \mathrm{dl}$ to $13 \mathrm{~g} / \mathrm{dl}$ [7].

This study was carried out because of the lack of clinical trials in a vulnerable population of elderly patients with heart failure, chronic kidney disease and anaemia.

The aim of this study was to determine the efficacy and safety of angiotensin inhibitors reduction in patients with heart failure, chronic kidney disease (creatinine clearance $<60 \mathrm{ml} / \mathrm{min} / 1.73 \mathrm{~m}^{2}$ ) and anaemia $(\mathrm{Hb}<12 \mathrm{mg} / \mathrm{dl})$, by conducting an open randomized controlled clinical trial.

The main goal of this study was to determine changes in haemoglobin and creatinine clearance after angiotensin inhibitor reduction. The secondary objective was to determine the probability of survival at 6 months and 1 year in the follow-up of this group of vulnerable patients. 


\section{Methods}

\section{Study design}

Open randomized controlled clinical trial.

\section{Setting}

Complexo Hospitalario Universitario A Coruña (Spain), with patients admitted to the Internal Medicine Service (A) in the period January-July 2009.

\section{Inclusion criteria}

Patients $\geq 50$ years old, with chronic heart failure, $\mathrm{Hb}<12 \mathrm{mg} / \mathrm{dl}$ and creatinine clearance $<60 \mathrm{ml} / \mathrm{min} / 1.73 \mathrm{~m}^{2}$ admitted to hospital, with angiotensin inhibitors treatment.

\section{Exclusion criteria}

Heart failure because of acute myocardial ischaemia; patients requiring devices or surgery (revascularization, valvular replacement, pacemakers, implantable cardioverter-defibrillators (ICD), heart transplantation, ventricular assist devices, artificial heart); pericardial disease; acute bleeding; pulmonary embolism; patients being treated with erythropoietin, ultrafiltration, haemodialysis and oncology patients.

\section{Measurements}

The following variables were established for each of the patients included in the study: age, gender, body mass index, presence of diabetes, symptoms and signs in the diagnosis of heart failure, severity of heart failure according to The New York Heart Association classification (NYHA), time since the diagnosis of heart failure; electrocardiogram, chest X-ray, echocardiography as well as haematology and biochemistry tests were conducted (at admission and 1-3 months after discharge), in particular: complete blood count (haemoglobin, haematocrit, leucocytes, platelets), serum electrolytes, S-creatinine, S-uric acid, S-urea, S-glucose, S-insulin, Shomocysteine, S-hepatic enzymes and urinalysis (proteinuria and glycosuria), Creatinine clearance, C-reactive protein (CRP), thyroid stimulating hormone (TSH).

\section{Intervention}

All of the patients with cardiac insufficiency received the treatment recommended in clinical practice guidelines [18] with respect to non-pharmacological and pharmacological therapy.

The dose of renin-angiotensin system inhibitors taken by the patients in the intervention group on admission was reduced by $50 \%$, while the control group continued to take the same dose of renin-angiotensin system inhibitors they were taking on admission.

The initial treatment dose and the dose after the intervention with angiotensin-converting enzyme inhibitor and angiotensin receptor antagonists in both groups are shown in Tables 1 and 2. 
Table 1. Characteristics of patients included in the study by group

\begin{tabular}{|c|c|c|c|c|c|}
\hline & \multicolumn{2}{|c|}{ Intervention group } & \multicolumn{2}{|c|}{ Control group } & \multirow{2}{*}{$\mathbf{p}$} \\
\hline & $\mathbf{n}$ & Mean \pm SD & $\mathbf{n}$ & Mean \pm SD & \\
\hline Age (years) & 30 & $78.2 \pm 7.8$ & 17 & $74.2 \pm 5.9$ & 0.079 \\
\hline BMI (weight/height ${ }^{2}$ ) & 28 & $27.5 \pm 4.9$ & 15 & $29.1 \pm 4.5$ & 0.316 \\
\hline Haemoglobin (g/dl) & 30 & $10.6 \pm 0.87$ & 17 & $10.7 \pm 1.02$ & 0.735 \\
\hline Haematocrit (\%) & 30 & $31.7 \pm 2.65$ & 17 & $32.16 \pm 2.85$ & 0.547 \\
\hline Plasmatic creatinine (mg/dl) & 30 & $1.97 \pm 0.73$ & 17 & $1.61 \pm 0.36$ & 0.068 \\
\hline Creatinine clearance $(24-\mathrm{h})\left(\mathrm{ml} / \mathrm{min} / 1.73 \mathrm{~m}^{2}\right)$ & 30 & $31.97 \pm 13.34$ & 17 & $47.5 \pm 8.74$ & $<0.001$ \\
\hline Albuminury (mg/24 h) & 28 & $0.39 \pm 0.58$ & 16 & $0.86 \pm 1.23$ & 0.130 \\
\hline Ejection fraction $(\%)$ & 29 & $48.20 \pm 16.28$ & 17 & $47.41 \pm 11.7$ & 0.862 \\
\hline Time of heart failure diagnosis (years) & 30 & $5.03 \pm 3.95$ & 17 & $4.29 \pm 3.98$ & 0.542 \\
\hline \multicolumn{6}{|l|}{ Angiotensin inhibitors treatment at admission } \\
\hline Angiotensin-converting-enzyme inhibitor (mg) (Enalapril) & 18 & $8.3 \pm 5.7$ & 6 & $5.8 \pm 2.0$ & 0.494 \\
\hline \multirow[t]{2}{*}{ Angiotensin receptor antagonists (mg) (Losartan) } & 12 & $56.2 \pm 35.6$ & 11 & $52.3 \pm 26.1$ & 0.928 \\
\hline & $\mathbf{n}$ & $\%$ & $\mathbf{n}$ & $\%$ & $\mathbf{p}$ \\
\hline \multicolumn{6}{|l|}{ Gender } \\
\hline Male & 16 & $59.3 \%$ & 11 & $40.7 \%$ & \multirow{2}{*}{0.449} \\
\hline Female & 14 & $70.0 \%$ & 6 & $30.0 \%$ & \\
\hline \multicolumn{6}{|l|}{ NYHA Classification } \\
\hline I & 5 & $62.5 \%$ & 3 & $37.5 \%$ & \multirow{4}{*}{0.736} \\
\hline II & 19 & $67.9 \%$ & 9 & $32.1 \%$ & \\
\hline III & 6 & $54.5 \%$ & 5 & $45.5 \%$ & \\
\hline IV & - & - & - & - & \\
\hline \multicolumn{6}{|l|}{ Diabetes } \\
\hline No & 18 & $69.2 \%$ & 8 & $30.8 \%$ & \multirow[t]{2}{*}{0.391} \\
\hline Yes & 12 & $57.1 \%$ & 9 & $42.9 \%$ & \\
\hline
\end{tabular}

BMI, body mass index; NYHA, New York Heart Association Functional Classification; SD, standard deviation. 
Table 2. Changes in the parameters studied during follow-up in the treatment and control groups

\begin{tabular}{|c|c|c|c|c|c|c|c|c|}
\hline & \multicolumn{4}{|c|}{ Intervention group } & \multicolumn{4}{|c|}{ Control group } \\
\hline & Admission & 1-3 months after discharge & & & & $\begin{array}{l}\text { 1-3 months after } \\
\text { discharge }\end{array}$ & & \\
\hline & Mean \pm SD & \multicolumn{3}{|l|}{ Mean \pm SD } & Mean \pm SD & \multicolumn{3}{|l|}{ Mean \pm SD } \\
\hline Haemoglobin $(\mathrm{g} / \mathrm{dl})$ & $10.6 \pm 0.9$ & $11.5 \pm 1.1$ & $<0.001$ & $8 \%$ & $10.6 \pm 1.0$ & $10.1 \pm 1.6$ & 0.198 & $-4.9 \%$ \\
\hline Haematocrit (\%) & $31.7 \pm 2.8$ & $34.4 \pm 3.1$ & $<0.001$ & $8.6 \%$ & $32.0 \pm 2.9$ & $30.4 \pm 4.7$ & 0.212 & $-4.9 \%$ \\
\hline Plasmatic creatinine $(\mathrm{mg} / \mathrm{dl})$ & $1.9 \pm 0.7$ & $1.7 \pm 0.4$ & 0.004 & $-15.1 \%$ & $1.6 \pm 0.4$ & $1.5 \pm 0.4$ & 0.269 & $-6.3 \%$ \\
\hline Creatinine clearance $(24-\mathrm{h})\left(\mathrm{ml} / \mathrm{min} / 1.73 \mathrm{~m}^{2}\right)$ & $32.5 \pm 13.9$ & $42.9 \pm 20.7$ & 0.001 & $32 \%$ & $48.3 \pm 8.8$ & $41.7 \pm 11.9$ & 0.056 & $-13.5 \%$ \\
\hline C-reactive protein $(\mathrm{mg} / \mathrm{dl})$ & $3.2 \pm 2.9$ & $1.4 \pm 1.9$ & 0.008 & $-57.5 \%$ & $1.9 \pm 2.9$ & $3.1 \pm 5.9$ & 0.560 & $6.2 \%$ \\
\hline Homocysteine $(\mathrm{mmol} / \mathrm{L})$ & $23.4 \pm 9.0$ & $25.1 \pm 17.7$ & 0.454 & $7.6 \%$ & $22.2 \pm 5.4$ & $17.9 \pm 8.6$ & 0.208 & $-19.20 \%$ \\
\hline Albuminury (mg/24 h) & $0.43 \pm 0.6$ & $0.7 \pm 1.2$ & 0.231 & $5.9 \%$ & $0.6 \pm 0.9$ & $0.7 \pm 1.2$ & 0.537 & $9.40 \%$ \\
\hline \multirow[t]{2}{*}{ Insulin $(\mathrm{mcU} / \mathrm{ml})$} & $13.4 \pm 18.4$ & $9.5 \pm 3.9$ & 0.286 & $-29 \%$ & $12.3 \pm 8.7$ & $10.0 \pm 10.8$ & 0.132 & $18.40 \%$ \\
\hline & Admission & After randomization & \multicolumn{2}{|l|}{$\mathbf{p}$} & Admission & After randomization & \multicolumn{2}{|l|}{$\mathbf{p}$} \\
\hline Angiotensin-converting-enzyme inhibitor (mg) (Enalapril) & $8.3 \pm 5.7$ & $4.2 \pm 2.8$ & \multicolumn{2}{|l|}{0.047} & $5.8 \pm 2.0$ & $5.8 \pm 2.0$ & \multicolumn{2}{|l|}{0.999} \\
\hline Angiotensin receptor antagonists (mg) (Losartan) & $56.2 \pm 35.6$ & $28.1 \pm 17.8$ & \multicolumn{2}{|l|}{0.008} & $52.3 \pm 26.1$ & $52.3 \pm 26.1$ & \multicolumn{2}{|l|}{0.999} \\
\hline
\end{tabular}

$\mathrm{SD}$, standard deviation. 


\section{Main outcome measure}

The main objective of this study was to determine changes in haemoglobin and creatinine clearance after angiotensin-inhibitor reduction in patients with heart failure, chronic kidney disease and anaemia.

The efficacy was measured by haemoglobin and creatinine clearance assessment at admission and 1-3 months after discharge.

Efficacy in terms of the pro-inflammatory variables was determined by measuring $\mathrm{C}$ protein, base insulin and homocysteine levels at admission and 1-3 months after discharge.

All of the measurements were carried out in the same laboratory in the hospital.

The secondary objective was to determine survival probability at 6 months and 1 year after admission in the patient follow-up.

\section{Sample size}

The literature points to a high prevalence of chronic renal insufficiency in patients with cardiac insufficiency, of around 40\% [19]. In order to be included in our study, patients had to have renal insufficiency of at least grade III of the K/DOQ I (creatinine clearance $<60 \mathrm{ml} / \mathrm{min} / 1.73 \mathrm{~m}^{2}$ ). If the treatment is expected to improve this renal insufficiency by $28 \%$ (100\% vs. $72 \%$ ), for a confidence of $95 \%$ and a statistical power of $80 \%$ we require 30 patients in the intervention group and 15 in the control group with a bilateral approach. The intervention group included twice as many patients as the control group, as a likely benefit was expected in the intervention group, and the aim was to minimise the lack of this benefit in the control group.

If this sample size is considered for studying anaemia in patients, it can be affirmed that in order to detect a difference of $1.5 \mathrm{gr} / \mathrm{dl}(12 \mathrm{gr} / \mathrm{dl}$ vs. $10.5 \mathrm{gr} / \mathrm{dl})$ with a standard deviation of 1.4 (obtained from a sample of patients) for a confidence of $95 \%$ and a statistical power of $80 \%$, assuming a 5\% information loss with a bilateral approach, then the sample size required for each group would be 16 patients. In this study, there were 30 patients in the intervention group and 17 in the control group.

\section{Randomization}

In order to balance the group sizes, a restricted randomization protocol was used [20]. Blocked randomization was used with a block size of six and an allocation ratio of $2: 1$ (four subjects to one group and two to the other), with a total of eight blocks.

\section{Blinding}

This was an open clinical trial. Only those assessing outcomes were blinded after assignment to interventions.

\section{Statistical methods}

Intention to treat (ITT) analysis was carried out, together with a descriptive study of the variables included in the study. The quantitative variables are expressed as the mean $\pm \mathrm{SD}$. The qualitative variables are expressed as an absolute value and percentage, with a $95 \%$ estimate of the confidence interval. To compare the characteristics of the different groups (treatment vs. control) Student's $t$-test or the Mann-Whitney test were used as appropriate. 
The association of qualitative variables was estimated using the $\chi^{2}$ test. After verifying normality with the Kolmogorov-Smirnov test, Student's paired $t$-test or the Wilcoxon test were used as applicable to compare the base values with the values after discharge.

Actuarial survival analysis using Kaplan-Meier curves, the log-rank test and Cox's regression analysis were also carried out.

Clinical relevance was estimated by calculating the Absolute Risk Reduction (ARR), the Relative Risk Reduction (RRR) between those who received treatment and those who did not, and the number needed to treat (NNT) in order to prevent death [21].

Ethics

Informed consent of the patients and approval by Ethical Review Board were obtained (CEIC Code: 2008/327). European Clinical Trials database. EudraCT: 2008-008,480-10.

\section{Role of the funding source}

No funding.

\section{Results}

Table 1 shows the characteristics of the patients in the treatment and control groups. The patients were comparable in terms of age, BMI, base haemoglobin and haematocrit, albuminuria, ejection fraction and years of development of cardiac insufficiency. Furthermore, according to the NYHA classification there were no differences in terms of sex, dyspnoea or prevalence of diabetes. The patients in the intervention group had lower base creatinine clearance values than those in the control group; this difference was statistically significant.

The doses of angiotensin-converting enzyme inhibitor (mg) (enalapril) and angiotensin receptor antagonists (losartan) at admission were similar in both groups (Table 2).

The doses of angiotensin-converting enzyme inhibitor (mg) (enalapril) and angiotensin receptor antagonists (losartan) after randomization were statistically different in both groups (Table 2).

After angiotensin inhibitor reduction, it was observed that in the intervention group there was a significant increase in the haemoglobin values $(10.62-11.47 \mathrm{~g} / \mathrm{dl})$, haematocrit $(31.7-34.4 \%)$ and creatinine clearance $\left(32.5 \mathrm{ml} / \mathrm{min} / 1.73 \mathrm{~m}^{2}\right.$ to $\left.42.9 \mathrm{ml} / \mathrm{min} / 1.73 \mathrm{~m}^{2}\right)$, and a significant decrease in the values for creatinine $(1.98 \mathrm{mg} / \mathrm{dl}$ to $1.68 \mathrm{mg} / \mathrm{dl})$ in serum and a decrease in protein $\mathrm{C}$ $(3.23 \mathrm{mg} / \mathrm{dl}$ to $1.37 \mathrm{mg} / \mathrm{dl})$.

In the control group, there were no significant differences in any of the variables studied. In fact, certain adverse changes were observed, such as a decrease in haemoglobin, haematocrit and creatinine clearance values, and an increase in protein $\mathrm{C}$ values (Table 2).

Table 2 shows the differences before and after the study in the control group and intervention group. It reveals significant divergences in the previously commented variables for haemoglobin, haematocrit, creatinine clearance and protein C. In the intervention group, there was an increase in haemoglobin, haematocrit and creatinine clearance, and a decrease in protein $\mathrm{C}$ values. However, in the control group, haemoglobin, haematocrit and creatinine clearance values decreased, with an increase in protein $\mathrm{C}$ values.

In terms of the changes in relative size, it was observed that haemoglobin improved in the intervention group with respect to the base values by $8 \%$, the haematocrit by $8.6 \%$, and creatinine clearance by $32 \%$. In turn, the values of C-reactive protein decreased by $57.7 \%$. 
In the control group, these parameters not only failed to improve, but actually they worsened, with a reduction in the haemoglobin and haematocrit levels by $4.9 \%$, a decrease in creatinine clearance of $13.5 \%$, and an increase in protein $\mathrm{C}$ values of $6.22 \%$ (Table 2).

A correlation was revealed between the reduced drug dose and the changes in the parameter values obtained before and after treatment. The more the doses of angiotensin receptor antagonists were reduced, the more the $\mathrm{Hb}$ improved $(\mathrm{r}=0.314 ; \mathrm{p}=0.22)$, with creatinine clearance also improving significantly $(r=0.678 ; \mathrm{p}=0.003)$.

After 3 months, the global survival rate was $97.9 \%, 80.9 \%$ after 6 months, and $60.8 \%$ after 12 months. Taking individual results into consideration, it is evident that the survival rate was higher in the intervention group than in the control group (Figure 1). After 6 months it was $86.7 \%$ in the intervention group and $75 \%$ in the control group, while after 12 months it was $69.3 \%$ and $50 \%$, respectively.

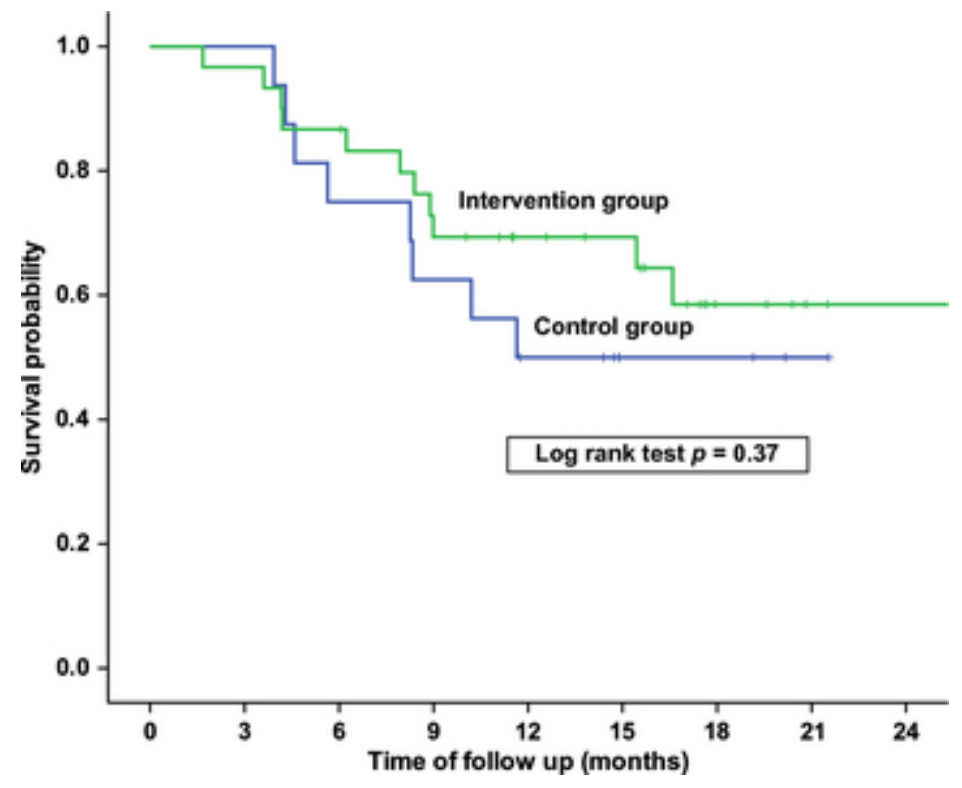

Figure 1. Survival probability by study group

On adjusting a multivariate Cox's regression model for the variables treatment group, age, base creatinine clearance, base haemoglobin and ejection fraction, it is evident that the only variable that significantly modified the prognosis was the belonging to the intervention group $(\mathrm{RR}=0.22)$ (Table 3). 
Table 3. Cox regression analysis to predict mortality in patients with heart failure adjusting for different covariables

\begin{tabular}{lllllll}
\hline & B & SE & p & RR & 95\% CI (RR) \\
\hline Intervention group vs. control group & -1.534 & 0.699 & 0.028 & 0.216 & 0.055 & 0.849 \\
Age (years) & 0.080 & 0.060 & 0.186 & 1.083 & 0.962 & 1.219 \\
Creatinine clearance (24-h) $\left(\mathrm{ml} / \mathrm{min} / 1.73 \mathrm{~m}^{2}\right)$ & -0.038 & 0.027 & 0.150 & 0.963 & 0.914 & 1.014 \\
Haemoglobin (g/dl) & 0.063 & 0.284 & 0.824 & 1.065 & 0.610 & 1.859 \\
Ejection fraction at admission $(\%)$ & -0.025 & 0.017 & 0.152 & 0.975 & 0.942 & 1.009 \\
& & & & & &
\end{tabular}

B, regression coefficient; SE, standard error; RR, relative risk; CI, confidence interval

Table 4 shows the clinical relevance estimated on the basis of the ARR, RRR between those who received the intervention and those who did not, and the Number Needed to Treat (NNT) in order to prevent death at 6 and 12 months. The table also shows that the clinical impact increases over longer follow-up periods. The ARR at 6 and 12 months was 0.10 and 0.17 respectively; the Relative Risk Reduction was 0.46 at 6 months and 0.36 at 12 months, and the Number Needed to Treat (NNT) was 10 at 6 months, and 6 at 12 months.

Table 4. Mortality rates in intervention and control groups, and indicators of clinical relevance

\begin{tabular}{|c|c|c|c|c|c|c|}
\hline & $\begin{array}{l}\text { Intervention } \\
\text { group }\end{array}$ & $\begin{array}{l}\text { Control } \\
\text { group }\end{array}$ & ARR & $\mathbf{R R}$ & RRR & NNT \\
\hline & & & & & & \\
\hline $\begin{array}{l}\text { 6-months } \\
\text { mortality }\end{array}$ & 4/30 (13.3\%) & $4 / 17(23.7 \%)$ & $\begin{array}{l}10.2 \%(-13.4 \% \\
33.7 \%)\end{array}$ & $\begin{array}{l}0.57(0.16 \\
1.98)\end{array}$ & $\begin{array}{l}43.3 \%(-98.1 \% \\
83.8 \%)\end{array}$ & $10(-8 ; 3)$ \\
\hline $\begin{array}{l}\text { 12-months } \\
\text { mortality }\end{array}$ & $9 / 30(30.0 \%)$ & $8 / 17(47.1 \%)$ & $17.1 \%(-11.8 ; 45.9)$ & $\begin{array}{l}0.64(0.30 \\
1.64)\end{array}$ & $\begin{array}{l}36.3 \%(-34.1 \% \\
69.7 \%)\end{array}$ & $6(-9 ; 3)$ \\
\hline
\end{tabular}

ARR, Absolute Risk Reduction; RR, relative risk; RRR, Relative Risk Reduction; NNT, number needed to treat

\section{Discussion}

The patients with cardiac insufficiency who took part in this study and met the inclusion criteria for anaemia $(\mathrm{Hb}<12 \mathrm{mg} / \mathrm{dl})$ and creatinine clearance $\left(<60 \mathrm{ml} / \mathrm{min} / 1.73 \mathrm{~m}^{2}\right)$ were similar in terms of the prevalence of diabetes, hypertension, chronic obstructive pulmonary disease and ischaemic cardiopathy to those included in other studies of patients with anaemia and cardiac insufficiency. [22-24].

Of the total patients, $97 \%$ of the patients were given angiotensin inhibitors, $80 \%$ were given diuretics, $55 \%$ beta-blockers and $21 \%$ calcium antagonists. Treatment with angiotensin inhibitors in this series is higher than that in other publications (GESAIC - 56\%, Nanas - 56.8\%) [22, 23].

In this study, anaemia corresponded to the chronic disorder pattern in $48.98 \%$ of the cases, followed by iron-deficiency anaemia in $27.6 \%$, which bears similarity to other series [23-25]. 


\section{Efficacy of the reduction of angiotensin inhibitors in anaemia treatment}

The renin-angiotensin system appears to be closely involved in the control of erythropoiesis. Angiotensin II decreases $\mathrm{pO} 2$ by reducing renal blood flow, and stimulates erythropoietin production. Angiotensin II also directly stimulates bone marrow erythroid progenitor cells [15, 16, $26,27]$.

The results obtained show that anaemia improves by reducing the dose of angiotensin inhibitors in patients with cardiac and renal insufficiency, and are consistent with the physiopathological mechanisms commented above and with other studies[15, 16, 28] that refer to the role these drugs play in causing anaemia.

In the SOLVD [28] study, the incidence of anaemia after 1 year of follow-up was $11.3 \%$ with enalapril, and $7.9 \%$ for the placebo group. The patients who developed de novo anaemia had a global mortality rate increased by $108 \%$, and in the multivariate analysis, a decrease of one point in the haematocrit was associated with an RR of 1.027 for mortality.

In the GESAIC [22] study, the variable with the highest risk associated with chronic anaemia was the angiotensin inhibitors (OR $=3.29$; $95 \%$ CI: $1.36-7.94)$.

When we compare the values from before treatment with those from after treatment in our clinical study, the reduction of angiotensin inhibitors led to a significant increase in the values of haemoglobin (10.62-11.47 g/dl) and haematocrit (31.7-34.4\%).

In the control group, there were no differences in any of the variables that were studied; in fact, a decrease in the haemoglobin and haematocrit values was observed.

\section{Efficacy of the reduction of angiotensin inhibitors in renal function improvement}

In this study, the patients in the intervention group presented a clear improvement in creatinine clearance, from $32.5 \mathrm{ml} / \mathrm{min} / 1.73 \mathrm{~m}^{2}$ to $42.9 \mathrm{ml} / \mathrm{min} / 1.73 \mathrm{~m}^{2}$ and a significant decrease in their creatinine values from $1.98 \mathrm{mg} / \mathrm{dl}$ to $1.68 \mathrm{mg} / \mathrm{dl}$, with a higher survival rate than the control group. There were no significant differences in any of the variables studied in the control group, and in fact, a decrease in the creatinine clearance values was revealed. Moreover, the more the dose of angiotensin receptor blockers was reduced, the greater the improvement in the $\mathrm{Hb}(\mathrm{r}=0.314$; $\mathrm{p}=0.22)$ was observed, with a significant creatinine clearance $(\mathrm{r}=0.678 ; \mathrm{p}=0.003)$.

The Cooperative North Scandinavian Enalapril Survival Study [29] showed that 20-30\% of patients presented reduced glomerular filtration rate after the introduction of enalapril.

In the CHARM [30] study, a correlation was revealed between different creatinine clearance levels and mortality.

\section{Results in terms of survival}

This study showed that after adjusting a Cox's regression analysis for the variables assigned group, patient age, creatinine clearance, haemoglobin and ejection fraction, the variable with an independent effect in predicting mortality was the intervention group $(R R=0.22)$.

After reducing the dose of angiotensin inhibitors, the risk of death was reduced by $43 \%$ with respect to the control group.

Felker et al. [31]. indicated an increase in the mortality rate of $3 \%$ for each one point decrease in the haematocrit.

The clinical relevance of this intervention is indicated by the Relative Risk Reduction $(\mathrm{RRR}=0.43)$ and Number Needed to Treat $(\mathrm{NNT}=10)$ after 6 and 12 months of follow-up $(\mathrm{RRR}=0.36, \mathrm{NNT}=6)($ Table 4$)$. 
In terms of the limitations of the study, it should be mentioned that although it was randomized, it was an open study. Blinding was not maintained neither for the clinician carrying out the intervention nor for the patient, as the study formed a part of the normal clinical practice in treating these patients.

This may have led to an information bias, although the response variables that comprised analytical and survival findings were entered into a database as anonymous data by people who were not directly involved in the study.

Follow-up was carried out in a similar way with both groups, so that surveillance bias, a type of non-random misclassification bias, is not applicable in the intervention group nor in the control group. All of the patients were examined with the same frequency and at the same intervals, with the same analytical findings during follow-up.

Although the groups were randomized, they were comparable in the majority of the variables of interest. However, the intervention group initially had lower creatinine clearance values than the control group. This difference was taken into account when adjusting the Cox's regression models. Even so, these values improved after intervention, and were higher than those of the control group.

Despite having a small sample size, statistically significant differences were found in the parameters of interest. This study has a statistical power of $80 \%$ and a confidence of $95 \%$ for detecting differences of at least $28 \%$ in the improvement of renal function, and the ability to detect a difference of $1.5 \mathrm{gr} / \mathrm{dl}$ in haemoglobin with the same confidence and statistical power.

The main objective of the study was not to determine the survival rate or prognostic factors of the patients after treatment, and the sample size was not calculated for this purpose, but instead the intention was to evaluate the incidence of anaemia and renal function after treatment. Despite not being a main objective, the survival rate was studied during the follow-up. For this reason, although there are differences in the mortality rate in the univariate analysis, the effect is not significant. In any event, after adjusting for the variables of interest, it was found in the regression model that belonging to the intervention group had an independent and statistically significant effect on reducing mortality.

\section{Contributions of the study}

This study clearly demonstrates the positive effect of reducing medication on the parameters that were studied. Significant differences were found in the reduction of anaemia, improvement of renal function and improvements in pro-inflammatory markers. After adjusting for the prognostic variables of interest, it was found that belonging to the intervention group was effective for improving anaemia, improving renal function and increased survival. It was also ascertained that the amount by which angiotensin-inhibiting drugs were reduced was related with the degree of improvement, which supports the hypothesis of a causal and dose-dependent relationship.

Our results are in line with the recommendations of the ACCF/AHA Guidelines for the Diagnosis and Management of Heart Failure in Adults [18], which state that worsening renal function may require adjustment of the doses of renin-angiotensin-aldosterone system antagonists.

Few authors have pointed to the importance of reducing the dose of angiotensin inhibitors in this subgroup of patients, as there is little evidence of the risks and benefits of these drugs in elderly patients [4].

These findings must be verified by subsequent studies, and if the results are found to be consistent, this will prove that reducing the drug dose, taking renal function into account, may have a clearly beneficial and clinically relevant effect for this group of patients. 


\section{Funding}

No funding was received to support this study.

\section{Author contributions}

SPF, TCF and SPD developed the study design and did the literature review. TCF, JJP and JDPA collected data for the study. SPF, SPD, TSP and BLC did the statistical analyses. SPF, TCF and VGG contributed to the writing of the report. All authors provided feedback on the study.

\section{References}

1. Abdo AS, Basu A, Geraci SA. Managing chronic heart failure patient in chronic kidney disease. Am J Med 2011; 124: 26-8.

2. Sarraf M, Masoumi A, Schrier RW. Cardiorenal syndrome in acute decompensated heart failure. Clin J Am Soc Nephrol 2009; 4: 2013-26.

3. Gottlieb SS, Abraham W, Butler J et al. The prognostic importance of different definitions of worsening renal function in congestive heart failure. J Card Fail 2002; 8: 136-41.

4. Málek F, Havrda M, Fruhaufová Z et al. Short-term effect of evidence-based medicine heart failure therapy on glomerular filtration rate in elderly patients with chronic cardiorenal syndrome. J Am Geriatr Soc 2009; 57: 2385-6.

5. Coca SG, Krumholz HM, Garg AX et al. Underrepresentation of renal disease in randomized controlled trials of cardiovascular disease. JAMA 2006; 296: 1377-84.

6. Silverberg DS, Wexler D, Iaina A et al. The interaction between heart failure and other heart diseases, renal failure, and anemia. Semin Nephrol 2006; 26: 296-306.

7. Silverberg DS, Wexler D, Blum M et al. The use of subcutaneous erythropoietin and intravenous iron for the treatment of the anemia of severe, resistant congestive heart failure improves cardiac and renal function and functional cardiac class, and markedly reduces hospitalizations. J Am Coll Cardiol 2000; 35: 1737-44.

8. Levin A, Thompson CR, Ethier $\mathrm{J}$ et al. Left ventricular mass index increase in early renal disease: impact of decline in hemoglobin. Am J Kidney Dis 1999; 34: 125-34.

9. Anand IS, Chandrashekhar Y, Ferrari R et al. Pathogenesis of oedema in chronic severe anaemia: studies of body water and sodium, renal function, haemodynamic variables, and plasma hormones. Br Heart J 1993; 70: 357-62.

10. Androne AS, Katz SD, Lund L et al. Hemodilution is common in patients with advanced heart failure. Circulation 2003; 107: 226-9.

11. Weiss G. Pathogenesis and treatment of anaemia of chronic disease. Blood Rev 2002; 16 87-96.

12. Opasich C, Cazzola M, Scelsi L et al. Blunted erythropoietin production and defective iron supply for erythropoiesis as major causes of anaemia in patients with chronic heart failure. Eur Heart J 2005; 26: 2232-7.

13. Iversen PO, Woldbaek PR, Tønnessen T et al. Decreased hematopoiesis in bone marrow of mice with congestive heart failure. Am J Physiol Regul Integr Comp Physiol 2002; 282: R166-72.

14. Torre-Amione G, Bozkurt B, Deswal A et al. An overview of tumor necrosis factor alpha and the failing human heart. Curr Opin Cardiol 1999; 14: 206-10.

15. Fyhrquist F, Karppinen K, Honkanen T et al. High serum erythropoietin levels are normalized during treatment of congestive heart failure with enalapril. J Intern Med 1989; 226: 257-60.

16. van der Meer P, Lipsic E, Westenbrink BD et al. Levels of hematopoiesis inhibitor Nacetyl-seryl-aspartyl-lysyl-proline partially explain the occurrence of anemia in heart failure. Circulation 2005; 112: 1743-7.

17. Al-Ahmad A, Rand WM, Manjunath G et al. Reduced kidney function and anemia as risk factors for mortality in patients with left ventricular dysfunction. J Am Coll Cardiol 2001; 38: $955-62$.

18. Jessup M, Abraham WT, Casey DE et al. 2009 focused update: ACCF/AHA Guidelines for the Diagnosis and Management of Heart Failure in Adults: a report of the American College of Cardiology Foundation/American Heart Association Task Force on Practice Guidelines: developed in collaboration with the International Society for Heart and Lung Transplantation. Circulation 2009; 119: 1977-2016.

19. Tang YD, Katz SD. Anemia in chronic heart failure: prevalence, etiology, clinical correlates, and treatment options. Circulation 2006; 113: 2454-61. 
20. Lachin JM, Matts JP, Wei LJ. Randomization in clinical trials: conclusions and recommendations. Control Clin Trials 1988; 9: 365-74.

21. Cook RJ, Sackett DL. The number needed to treat: a clinically useful measure of treatment effect. BMJ 1995; 310: 452-4.

22. Grau Amorós J, Formiga F, Jordana Comajuncosa R et al. Etiology and clinical management of anemia in heart failure GESAIC Study. Med Clin (Barc) 2009; 132: 44753.

23. Nanas JN, Matsouka C, Karageorgopoulos D et al. Etiology of anemia in patients with advanced heart failure. J Am Coll Cardiol 2006; 48: 2485-9.

24. Ezekowitz JA, McAlister FA, Armstrong PW. Anemia is common in heart failure and is associated with poor outcomes: insights from a cohort of 12065 patients with new-onset heart failure. Circulation 2003; 107: 223-5.

25. Weiss G, Goodnough LT. Anemia of chronic disease. N Engl J Med 2005; 352: 1011-23.

26. Cromie N, Lee C, Struthers AD. Anaemia in chronic heart failure: what is its frequency in the UK and its underlying causes? Heart 2002; 87: 377-8.

27. Albitar S, Genin R, Fen-Chong M et al. High dose enalapril impairs the response to erythropoietin treatment in haemodialysis patients. Nephrol Dial Transplant 1998; 13 : 1206-10.

28. The SOLVD Investigattors. Effect of enalapril on mortality and the development of heart failure in asymptomatic patients with reduced left ventricular ejection fractions. N Engl J Med 1992;327:685-91.

29. Ljungman S, Kjekshus J, Swedberg K. Renal function in severe congestive heart failure during treatment with enalapril (the Cooperative North Scandinavian Enalapril Survival Study [CONSENSUS] Trial). Am J Cardiol 1992; 70: 479-87.

30. Solomon SD, Anavekar N, Skali H et al. Influence of ejection fraction on cardiovascular outcomes in a broad spectrum of heart failure patients. Circulation 2005; 112: 3738-44.

31. Felker GM, Gattis WA, Leimberger JD et al. Usefulness of anemia as a predictor of death and rehospitalization in patients with decompensated heart failure. Am J Cardiol 2003; 92: $625-8$ 